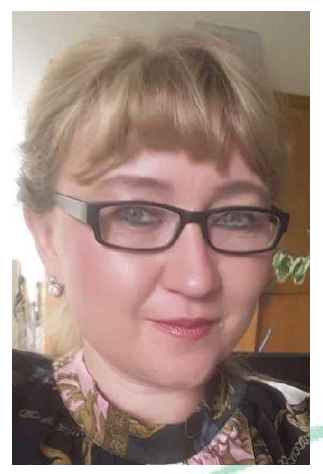

УДК 631.158:658.310.82

https://doi.org/10.47612/978-985-7149-55-1-2020-175-178

Ольга Пашкевич, кандидат экономических наук, доцент, заведующий сектором рынка труда

Институт системных исследований в АПК НАН Беларуси, г. Минск

\title{
Дилемма «количество - качество» в кадровом обеспечении сельскохозяйственных организаций
}

Эффективность хозяйствовати зависит от кадрового обеспечения. Современная демографическая ситуация, а также изменения, происходящие в агропромышленном комплексе, требуют государственного регулирования в отношении количества и качества трудовых ресурсов, процесса их воспроизводства, профессионального становления и привлечения в сельскохозяйственные организации $[3,4,7,11]$. Руководители и специалисты различного профиля создают основу социально-экономического развития сельского хозяйства. Вместе с тем новые социально-экономические реалии предъявляют новые требования к работнику, его квалификации, набору компетенций.

Мониторинг и оценка кадрового обеспечения сельскохозяйственных организаций свидетельствует, что потребность в работниках в связи с повышением уровня технико-технологической оснащенности сельскохозяйственной отрасли сокращается. Тем не менее в организациях сохраняется дефицит кадров, вызванный высокой их текучестью. Это вынуждает работодателей привлекать на имеющиеся вакансии работников с низким уровнем профессиональной подготовки, отсутствием практического опыта, неспособных соблюдать трудовую и технологическую дисциплину. В свою очередь, такая ситуация обусловливает формирование трудового потенциала субъектов АПК низкого качества [3].

Отсутствие положительной динамики заполняемости рабочих мест кадрами и привлечения их в сельскохозяйственные организации обусловлено низким уровнем заработной платы, ее несвоевременной выплатой и тяжелыми условиями труда (ненормированный рабочий день, непредоставление отпусков, компенсирующих выплат при привлечении к работе в сверхурочное время, выходные и праздничные дни). Номинальная начисленная заработная плата в сельском хозяйстве в 2019 г. составила 69,6\% от средней в экономике, в то время как в финансовой и страховой деятельности этот показатель значительно выше - 157,2 \%; государственном управлении - 121,5; информационных технологиях 396,2 ; информации и связи - 295,3\%. Средний возраст работников аграрной отрасли в 2019 г. - 43,9 года, доля молодежи в возрасте до 31 года - только 15,6 \%. Для сравнения: в сфере финансовой и страховой деятельности эти показатели составляют 38,8 года и $24,2 \%$; государственного управления - 40,3 и 22,3; информационных технологий - 32,4 и 49,6; информации и связи - 35,5 и 38,$7 ;$ торговле - 38,7 года и $28,8 \%$ соответственно.
В результате оттока молодежи из села, низкой рождаемости, обострившихся в последнее время социальных проблем наметилась устойчивая тенденция старения сельского населения. Кроме того, ускоряются темпы естественной убыли сельского населения республики. За последние три года его численность сократилась на 11875 чел., в том числе в трудоспособном возрасте - на 4892 чел. В настоящее время жители пенсионного возраста составляют около $33 \%$ в структуре сельского населения, и данный процесс (по демографическому прогнозу) в ближайшие годы будет прогрессировать. Это свидетельствует о сужении базы для воспроизводства трудовых ресурсов села. Кадровый потенциал субъектов хозяйствования республики формируется в сложной социально-демографической обстановке, когда численность и доля трудоспособного населения и молодежи в сельской местности снижаются. Следует отметить, что при такой тенденции эффективность кадровой политики будет зависеть от технико-технологической модернизации отрасли, а также опережающей подготовки высококвалифицированных кадров на модернизированные рабочие места.

Такая динамика привела к тому, что в сельской местности сократилось количество учреждений дошкольного, среднего общего, профессионально-технического образования и численность обучающихся в них (табл. 1-3).

Для развития и повышения конкурентоспособности отечественного аграрного сектора особое значение имеет привлечение в отрасль профессионального управленческого персонала и квалифицированных кадров массовых профессий.

По состоянию на 01.01.2020 г. в сельскохозяйственных организациях республики работает 51,1 тыс. руководящих работников и специалистов, 213,3 тыс. рабочих кадров. Заполняемость рабочих мест руководящими работниками и специалистами по республике составляет порядка $92 \%$. В сельскохозяйственных организациях вакантны 4629 рабочих мест руководящих работников и специалистов. Выше республиканского уровня заполняемость рабочих мест управленческого персонала только в Брестской $(94,9 \%)$ и Могилевской (95,7\%) областях.

Из-за недостаточной профессиональной подготовленности к новым условиям хозяйствования, отсутствия навыков управления производственными процессами, обострившихся социально-экономических проблем, низкого уровня заработной платы в последние годы темпы выбытия и сменяемости руководителей и специалистов были высокими, ухудшился качественный состав. 
Таблица 1. Количество дошкольных образовательных учреждений в сельских населенных пунктах (на начало учебного года)

\begin{tabular}{|l|c|c|c|c|c|c|c|c|}
\hline \multirow{2}{*}{ Показатели } & \multicolumn{9}{|c|}{ Учебный год } & $\begin{array}{c}2019 / 20 \text { к } \\
2013 / 14, \%\end{array}$ \\
\cline { 2 - 10 }$n n$ & $2013 / 14$ & $2014 / 15$ & $2015 / 16$ & $2016 / 17$ & $2017 / 18$ & $2018 / 19$ & $2019 / 20$ & 85,4 \\
\hline Число учреждений, ед. & 1982 & 1919 & 1884 & 1803 & 1729 & 1713 & 1692 & 53,3 \\
\hline $\begin{array}{l}\text { Численность детей, } \\
\text { тыс. чел. }\end{array}$ & 63,0 & 61,1 & 59,0 & 59,0 & 59,2 & 59,3 & 58,8 & 93,3 \\
\hline
\end{tabular}

Примечание. Таблицы 1-3 составлены по данным [5, 9].

Таблица 2. Количество учреждений общего среднего образования в сельских населенных пунктах (на начало учебного года)

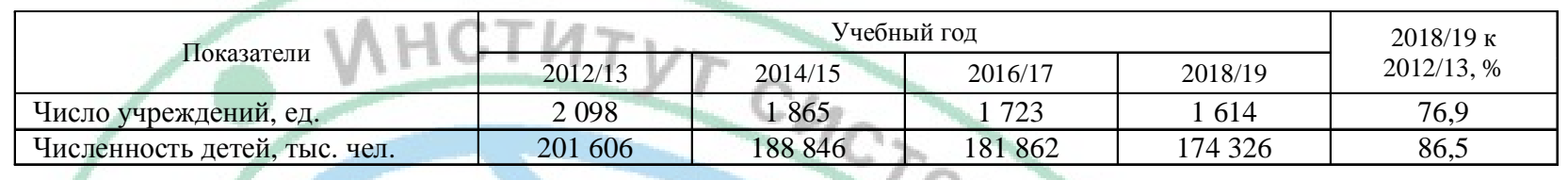

Таблица 3. Количество учреждений профессионально-технического образования (на начало учебного года)

\begin{tabular}{|l|c|c|c|c|c|c|c|c|}
\hline \multirow{2}{*}{ Показатели } & \multicolumn{7}{c|}{ Учебный год } & \multirow{2}{2}{$\begin{array}{c}2019 / 20 \text { к } \\
2013 / 14, \%\end{array}$} \\
\cline { 2 - 10 } & $2013 / 14$ & $2014 / 15$ & $2015 / 16$ & $2016 / 17$ & $2017 / 18$ & $2018 / 19$ & $2019 / 20$ & 80,4 \\
\hline Число учреждений, ед. & 219 & 213 & 206 & 196 & 182 & 180 & 176 & 85,0 \\
\hline Численность учащихся, тыс. чел. & 74,6 & 72,8 & 72,2 & 70,3 & 66,9 & 65,7 & 63,4 & 82,1 \\
\hline Принято учащихся, тыс. чел. & 34,6 & 34,5 & 33,7 & 32,0 & 29,7 & 30,3 & 28,4 & 8 \\
\hline $\begin{array}{l}\text { Выпущено квалифицированных } \\
\text { рабочих (служащих), тыс. чел. }\end{array}$ & 36,9 & 33,8 & 31,1 & 31,2 & 30,5 & 29,0 & 28,0 & 75,9 \\
\hline
\end{tabular}

Так, доля уволенных руководящих работников и специалистов в 2019 г. составила 14,7\%. Наиболее высокий данный показатель в организациях Витебской и Гомельской областей $(16,7$ \%). Высшее образование имеют 46,9\% руководящих работников и специалистов сельскохозяйственных организаций республики, лишь в Гродненской области $-50,2 \%$. Численность управленческих работников и специалистов в экономически активной возрастной категории до 31 года в 2019 г. составляла 23,9\% (в 2018 г. $-24,8 \%$ ).

По состоянию на 01.01.2020 г. в республике имеется 143 вакансии рабочих мест руководителей сельскохозяйственных организаций, наиболее проблемными являются предприятия Гомельской (49 вакансий) и Минской (50 вакансий) областей. Высшее образование имеют $94 \%$ руководителей сельскохозяйственных организаций республики, среднее специальное - 5,7 \%. Наименьшее количество руководителей с высшим образованием в хозяйствах Витебской $(89,5 \%)$ и Могилевской $(88,8 \%)$ областей.

Заполняемость рабочих мест кадрами рабочих профессий составляет $95 \%$, в том числе трактористами-машинистами - 91, водителями - 92, рабочими, обслуживающими животноводство - 97, операторами машинного доения - $94 \%$. Однако, как показывает практика, среди профессиональных групп рабочих кадров более высокая квалификация (степень и вид профессиональной обученности, необходимой для выполнения конкретного вида работы) у механизаторов и водителей (удельный вес механизаторов и водителей I и II класса составляет более 50 \% их общей численности). Изучение качественного состава работников животноводства показало, что более высокий уровень подготовки у операторов машинного доения, крайне низкая квалификация у работников, обслуживающих молодняк и рабочий скот на откорме. Учитывая, что в настоящее время работники животноводческой отрасли составляют $36 \%$ всех рабочих кадров сельскохозяйственных организаций, проблема подготовки кадров для животноводства по экономической значимости является одной из главных.

Кроме того, низкая квалификация рабочих кадров сдерживает сущностное преобразование функций специалистов разных уровней управления, которое заключается в освоении инновационных техники и технологий и внедрении их в производство. Вместо этого специалисты заняты преимущественно регламентированием организации производственного процесса и осуществлением оперативных и контролирующих функций.

Система аграрного образования Республики Беларусь в целом обеспечивает подготовку кадров в соответствии с запросами отрасли (рис.). Открываются новые специальности, этим самым подготовка кадров адаптируется к потребностям аграрного производства. Однако совокупность нерешенных проблем и негативных факторов еще не позволяют обеспечить стабильное привлечение в аграрный сектор республики профессионально подготовленных работников, обладающих созидательной активностью и творческим подходом к труду.

Несмотря на существующую широкую сеть учреждений образования сельскохозяйственного профиля всех уровней, за последние годы в организациях АПК постоянно востребованы специалисты отраслевого и технико-технологических направлений: агрономы, зоотехники, ветеринарные врачи, инженеры и т. д. В частности, в сельскохозяйственных организациях всех областей имеются вакантные рабочие места специалистов зооветеринарного профиля (ветеринарных врачей - 930, зоотехников-658). 


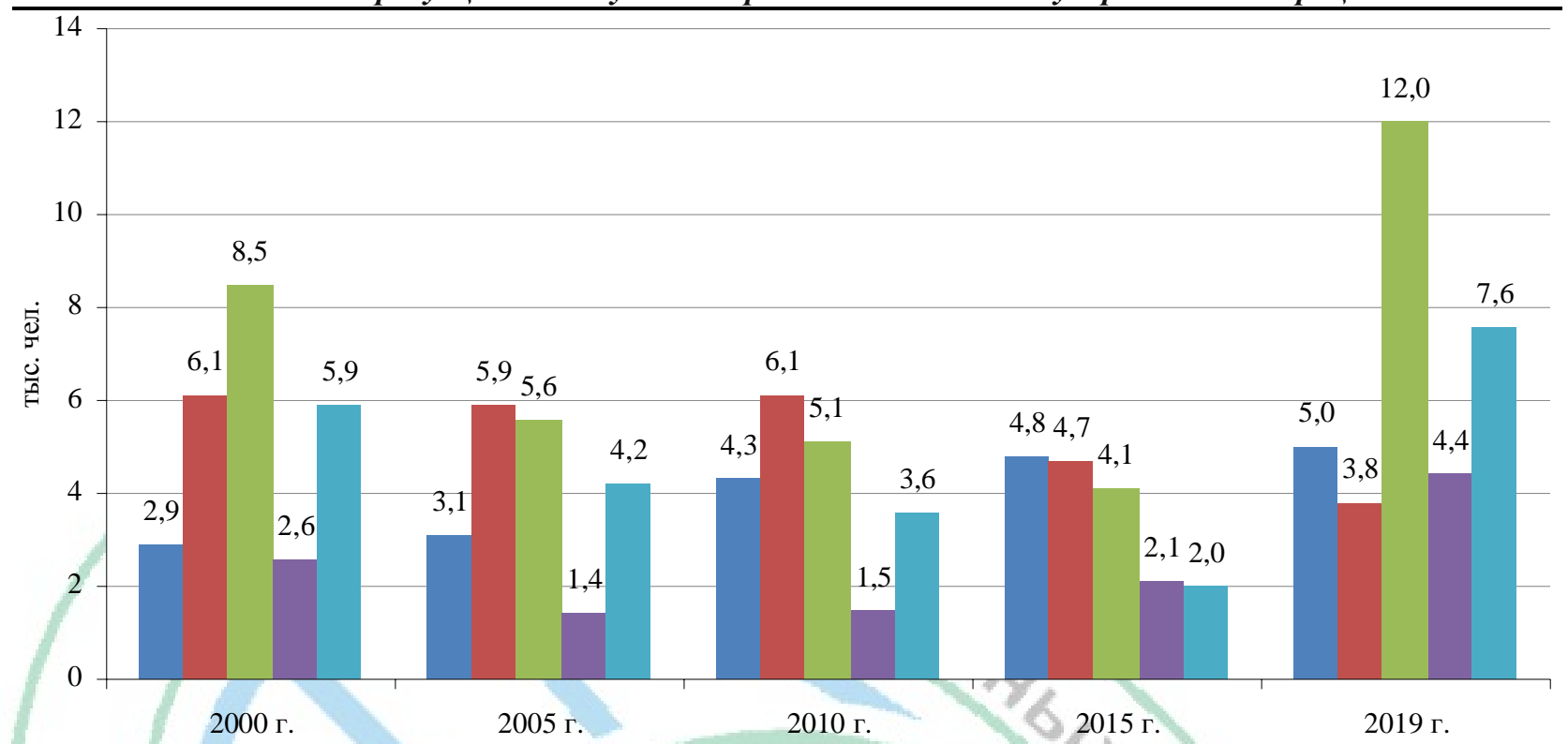

Выпуск специалистов учреждениями высшего образования по профилю «Сельское хозяйство»

Выпуск специалистов учреждениями среднего специального образования по профилю «Сельское хозяйство»

Потребность в работниках, заявленная сельхозорганизациями в органы по труду, занятости и социальной защите - всего

Руководители и специалисты

Рабочие кадры

Рис. Подготовка кадров для сельскохозяйственных организаций и заявленная потребность в приеме работников, тыс. чел.

Примечание. Рисунок составлен по данным $[8,10]$.

Сложившаяся ситуация требует разрешения дилеммы «количество - качество» в кадровом обеспечении субъектов хозяйствования аграрной сферы. С этой целью сформированы профильные агроклассы, которые призваны способствовать сознательному выбору профессии наряду с проводимыми мероприятиями профориентационной работы [1]. Вместе с тем функционирует механизм целевой подготовки специалистов для сельскохозяйственных организаций как процесс взаимодействия профессиональных учебных заведений с организациями и другими заинтересованными сторонами с целью установления баланса между спросом и предложением на рынке труда и рынке образовательных услуг [2].

Практика показывает, что решить проблему привлечения кадров в сельскохозяйственные организации формальным увеличением контрольных цифр приема абитуриентов не имеет под собой достаточных оснований, как и заполнение учебных мест в учреждениях системы аграрного образования за счет выпускников аграрных классов, о чем свидетельствуют следующие данные. Так, например, в 2020 г. план целевого приема на специальность «Зоотехния» выполнен на 24,5\%, «Ветеринарная медицина»- на 53,4 \%. В 2020 г. из 1166 выпускников агроклассов на обучение в аграрные вузы зачислено 156 чел. (13,4 \% от выпуска), из них на условиях целевой подготовки - 104 чел.

Такая ситуация предопределяет анализ и оценку глубинных причин сложившейся ситуации с кадровым обеспечением сельского хозяйства, отсутствия стимулов к производительному труду, кризиса системы мотивации труда. Демографическая ситуация не позволяет сформировать достаточный набор абитуриентов из сельской местности. Следует расширить такую подготовку и для городских школьников в рамках реализации ознакомительного курса «Введение в аграрные профессии» (например, посредством презентации об объектах агрокультурного наследия в Беларуси) как образовательного компонента [6].

Проблема устойчивого развития аграрного производства заключается не в декларируемом дефиците кадров (их объемах подготовки), а в сложившейся в сельскохозяйственных организациях модели социально-трудовых отношений между работниками и нанимателями (предприятиями), включая механизм и инструменты мотивации труда. Вопрос подготовки аграрных кадров не актуален - их готовится достаточное количество. При имеющемся уровне механизации и автоматизации производственных процессов необходимо повышение их качества.

Основной причиной недостаточной мотивации труда в сельскохозяйственных организациях и, следовательно, хронического дефицита кадров в них является низкий уровень заработной платы. Аграрные предприятия с достойной заработной платой, как правило, не имеют проблем с комплектованием кадров. Многие работники дефицитных на рынке аграрного труда профессий трудоустраиваются в другие отрасли, зачастую не по специальности. Из этого следует вывод, что существующая в сельском хозяйстве система заработной платы и использования кадров снижает престиж высшего образования, подрывает стимулы к производительному труду [7].

Несмотря на достаточное количество подготовленных специалистов, сельскохозяйственные организации не могут обеспечить себя трудовыми ресурсами. 
Причина здесь не в количестве подготавливаемых кадров, а в их текучести. Сельскохозяйственные организации в силу сложного финансового положения (навязанная закредитованность, существующая ведомственная подчиненность предприятий системы Минсельхозпрода, нерешенность, «размытость» и противоречивость вопросов собственности) не в состоянии обеспечить наём необходимых кадров на рынке рабочей силы [7]. Молодые специалисты трудоустраиваются в отрасли, где цена спроса на их рабочую силу выше. Поэтому субъекты хозяйствования аграрной сферы испытывают не количественный, а структурный и компетентностный (качественный) дефицит кадров. В некоторых сельскохозяйственных организациях он приобретает хронический характер.

Выход из сложившейся ситуации видится в формировании модели управления занятостью трудовых ресурсов в аграрном производстве, в основе которой - предпринимательская форма управления, позволяющая повысить мотивацию к эффективной производственной деятельности персонала сельскохозяйственной организации. Предлагается заключение договора между учреждениями системы аграрного образования и работодателем о создании комфортных условий труда и жизни для молодого специалиста на селе. В этой связи нами выработаны критерии для двух сторон данного договора:

для учреждений образования - подготовка специалиста с уровнем компетенций, требуемых для осуществления эффективного сельскохозяйственного производства;

для сельскохозяйственных организаций (работодателей) - перечень норм научной организации и охраны труда и социальных стандартов жизни молодого специалиста на селе.

В случае невыполнения и (или) нарушения прав и обязанностей сторонами договора молодой специалист вправе обратиться в комиссию по распределению и перераспределению с заявлением направить его в другую сельскохозяйственную организацию.

В случае если учебное заведение подготовило работника ненадлежащего профессионально-квалификационного уровня, то руководитель сельскохозяйственной организации имеет право обратиться в учебное заведение за новым специалистом соответствующей квалификации.

В связи с обострением проблем кадрового обеспечения аграрной отрасли (особенно зоотехниками, ветеринарами, кадрами рабочих профессий в животноводстве), высокой текучести сельскохозяйственных кадров, следует усилить координацию проектов государственной программы «Аграрный бизнес» на 2021-2025 годы и программы кадрового обеспечения отрасли. Это позволит нивелировать дилемму «количество - качество», сбалансировать показатели кадрового обеспечения с объемами их подготовки в системе аграрного образования.

\section{Список использованных источников}

1. Дубежинский, Е. В. Агроклассы - новая реальность / Е. В. Дубежинский, Н. Г. Трапянок, Е. И. Вильдфлуш. - Горки : БГСХА, 2020. - 35 с.

2. Дубежинский, Е. В. Целевая подготовка специалистов для организаций АПК / Е. В. Дубежинский, Н. Г. Трапянок, Е. И. Вильдфлуш. - Горки : БГСХА, 2019. $47 \mathrm{c}$.

3. Исследование теоретических основ и методологических подходов к формированию нового качества трудового потенциала АПК, системы мотивации труда, основанной на политике социального партнерства / О. А. Пашкевич [и др.] // Перспективные направления современного развития АПК: вопросы теории и методологии / В. Г. Гусаков [и др.]; редкол.: В. Г. Гусаков (гл. ред.) [и др.]; под ред. В. Г. Гусакова. -Минск : Ин-т систем. исслед. в АПК НАН Беларуси, 2020. - Гл. 4, § 4.3.-С. 118-131.

4. Лаврухина, Е. А. Парадоксы трудоустройства выпускников аграрных вузов / Е. А. Лаврухина // Высш. образование в России. - 2011. - № 2. - С. 126-130.

5. Образование в Республике Беларусь: стат. сб. / Нац. стат. ком. Респ. Беларусь. - Минск, 2020. - 187 с.

6. Пашкевич, О. А. Агрокультурное наследие: истоки, реалии, перспективы / О. А. Пашкевич // Наука и инновации. -2020 . - № 9. - С. 37-42.

7. Пашкевич, О. А. Проблемы и направления совершенствования порядка оплаты труда в сельскохозяйственных организациях // О. А. Пашкевич, В. О. Лёвкина // Экономические вопросы развития сельского хозяйства Беларуси: межвед. темат. сб. / Ин-т систем. исслед. в АПК НАН Беларуси ; редкол. : В. Г. Гусаков [и др.]. - Минск, 2019. Вып. 47. - С. 236-246.

8. Сельское хозяйство Республики Беларусь: стат. сб./ Нац. стат. ком. Респ. Беларусь. - Минск, 2020. - 179 с.

9. Статистический ежегодник Республики Беларусь 2020: стат. сб. / Нац. стат. ком. Респ. Беларусь. - Минск, 2020. $-436 \mathrm{c}$.

10. Труд и занятость в Республике Беларусь: стат. сб. / Нац. стат. ком. Респ. Беларусь. - Минск, 2020. $316 \mathrm{c}$.

11. Ушачев, И. Сельскохозяйственные кадры: дефицит при избытке / И. Ушачев, В. Еремеев, Н. Жуков // АПК: экономика, управление. - 2017. - № 2. - С. 15-26. 